\title{
Extrusion of Polymer Nanocomposites with Graphene and Graphene Derivative Nanofillers: An Overview of Recent Developments
}

\author{
José Sanes *, Cristian Sánchez ${ }^{\circledR}$, Ramón Pamies $®$, María-Dolores Avilés@ and \\ María-Dolores Bermúdez \\ Grupo de Ciencia de Materiales e Ingeniería Metalúrgica, Campus de la Muralla del Mar., Universidad \\ Politécnica de Cartagena, 30202 Cartagena, Spain; cristian.sanchez@upct.es (C.S.); ramon.pamies@upct.es (R.P.); \\ mdolores.aviles@upct.es (M.-D.A.); mdolores.bermudez@upct.es (M.-D.B.) \\ * Correspondence: pepe.sanes@upct.es
}

Received: 29 November 2019; Accepted: 21 January 2020; Published: 23 January 2020

check for updates

\begin{abstract}
This review is focused on the recent developments of nanocomposite materials that combine a thermoplastic matrix with different forms of graphene or graphene oxide nanofillers. In all cases, the manufacturing method of the composite materials has been melt-processing, in particular, twin-screw extrusion, which can then be followed by injection molding. The advantages of this processing route with respect to other alternative methods will be highlighted. The results point to an increasing interest in biodegradable matrices such as polylactic acid (PLA) and graphene oxide or reduced graphene oxide, rather than graphene. The reasons for this will also be discussed.
\end{abstract}

Keywords: thermoplastics; graphene; graphene oxide; extrusion; nanocomposites

\section{Introduction}

The fabrication of nanocomposites by the incorporation of nanofillers into polymer matrices originates materials with new functional properties while the excellent processing and manufacturing abilities are retained due to the flexibility in polymer matrices [1]. In recent years, the addition of different types of graphene $(G)$ nanofillers has been attempted as a method to improve the mechanical and functional properties of a variety of thermoplastic matrices [2,3]. Graphene-based composites have demonstrated potential for applications in several technological fields such as energy storage [4,5], environmental applications [6] and biomedical usage [7-9].

Industrial thermoplastic polymers and composites are usually melt-processed by extrusion followed by injection molding. The extrusion step combines the application of high temperature and high specific mechanical energy in a short time interval. The optimization of extrusion parameters plays a fundamental role on the final properties of the material. Extrusion elements configuration and parameters such as residence time, screw speed, temperature and energy are even more critical when nanocomposites are concerned $[10,11]$. The final objective is to improve nanophase dispersion.

The original definition of graphene [12] is that of a single layer bidimensional structure of carbon atoms; however, the literature includes a few different carbon nanofillers under the common denomination of graphene [13].

Methods for achieving the dispersion of graphene in polymer matrices [14] usually include the use of a solvent in which both graphene and the polymer are dispersed and then co-precipitated [15]. Alternatively, the solvent is evaporated, and the dried dispersion is obtained as a film [16,17]. Another method that consists of adding graphene to the monomer before polymerization is carried out to obtain the corresponding composite material $[18,19]$. The following are the three main methods applied in obtaining polymer-graphene nanocomposites: 
- Solvent processing. The use of conventional solvents causes serious health and environmental problems which prevent the large-scale usage of these procedures.

- In situ polymerization. This is an effective method to obtain small quantities of materials for laboratory research applications but not for industrial scale.

- Melt blending. Several thermoplastic matrices have been modified by melt blending addition of different forms of graphene oxide (GO) and reduced graphene oxide (rGO) nanofillers. However, this process might cause defects in the GO structure, from wrinkles and rolling, to modification of the initial aspect ratio.

Methods using a solvent need the previous modification of graphene surface in order to disperse it. In situ polymerization can be more efficient. However, both methods are not readily scaled to industrial processing. In contrast with solvent dispersion and in-situ polymerization processes, melt processing, that is, the direct dispersion of graphene nanophases into molten polymer is a cleaner process that can be readily scaled up for industrial applications. However, in order to achieve uniform graphene dispersion into highly viscous polymers, it is still necessary to modify the surface of graphene flakes. Although this modification can be made by chemical functionalization, with the formation of new covalent bonds [20], it can be more convenient to use a milder process involving non-covalent surface modification [21]. The ease of preparation of large amounts of graphene oxide, the relatively simple dispersion into polymer matrices and the affinity of GO surface oxygen-containing functional groups towards some macromolecules has made it the nanofiller of choice in many cases.

Melt-processing is usually performed by twin-screw extrusion, which is an environmentallyfriendly method immediately applicable to the industrial scale manufacturing of final parts. The versatility of this process allows tailoring the extrusion parameters for each material and application. This method is widely used for the processing of nanocomposites, since the mixing action is based on an elongational flow. Shear and elongation stresses are as the material is transported through the space between screws (typically of the order of a few micrometers) [22].

Another advantage of extrusion could be the alignment of planar nanostructures such as those of graphene nanomaterials in one preferential direction. Kim et al. [23] have discussed the degree of alignment in polycarbonate-graphene nanocomposites as a function of manufacturing process. Nevertheless, the control and reproducibility of dispersion and orientation of GO inside polymer matrices are complex technical problems which, in most cases, remain to be solved [24]. In order to overcome the Van der Waals forces between graphene layers with an interaction energy of about $2 \mathrm{eV} / \mathrm{nm}^{2}$, the order of magnitude of the force necessary to exfoliate the graphite is about $300 \mathrm{nN} / \mathrm{mm}^{2}$ [25-27], which is very difficult to achieve.

Research interest in nanocomposite materials containing graphene has been present for more than a decade [28], as it begun very shortly afterwards the first description of graphene. The problems associated with the preparation and stability of graphene dispersions for final applications have been the object of previous reviews [26-30]. This review reports a brief overview on the recent research dealing with the formulation of polymer-based nanocomposites containing graphene or graphene oxide. In all cases, the manufacturing method of the reviewed composite materials has been melt-processing, in particular, twin-screw extrusion, which can then be followed by injection molding. Especial interest is devoted to the thermoplastic graphene nanocomposites melt-processed by extrusion and also to the biodegradable and biocompatible polymers.

\section{Graphenic Nanofillers}

As it is mentioned above, there are several kinds of carbon nanofiller that are commonly called graphene. The basic structure of the different graphenic nanomaterials is graphene [31]. This nanomaterial is described as planar sheet of one-atom thickness, composed by carbon atoms with sp ${ }^{2}$ hybridization. As it is depicted in Figure 1, these carbon atoms are displayed into a honeycomb lattice. The carbon atoms are bound by means of two single and one double covalent bond to the three adjoining atoms [32,33]. The graphitic structure consists in multi-layered graphene sheets, and it is considered 
that $\mathrm{G}$ can be found in different arrangements, such as: graphene monolayers, graphene nanosheets and graphene nanoplatelets (GnPs) [34,35]. This nanomaterial exhibits remarkable attributes such as mechanical, electrical and thermal properties, among others, which are summarized in Table 1 [36-38].
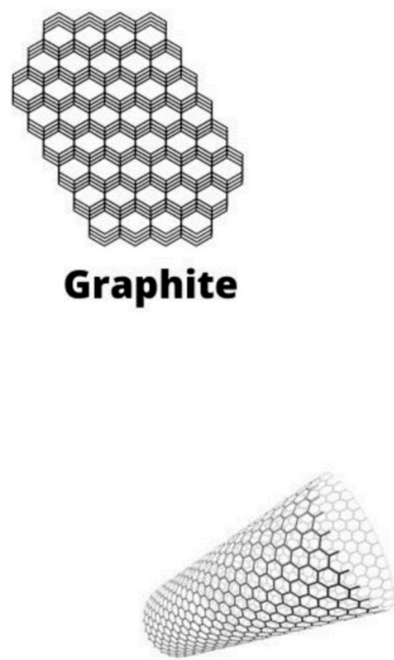

Carbon nanotube

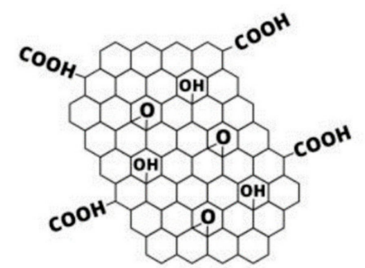

Graphene oxide

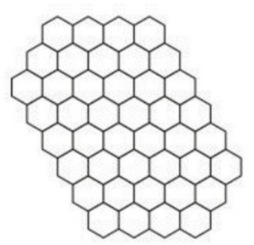

Graphene

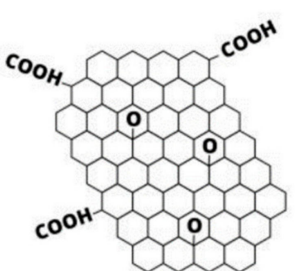

\section{Reduced graphene} oxide

Figure 1. Structures of the most common graphenic nanofillers [38].

Table 1. Mechanical and functional properties of pristine graphene.

\begin{tabular}{cc}
\hline \multicolumn{2}{c}{ Mechanical Properties } \\
\hline $\begin{array}{c}\text { Young's modulus } \\
\text { Fracture Strength }\end{array}$ & $130 \mathrm{TPa}$ \\
\multicolumn{2}{c}{ Electrical Properties } \\
\hline \multicolumn{2}{c}{ Other Properties } \\
\hline \multicolumn{2}{c}{$10^{4} \mathrm{~S} / \mathrm{cm}$} \\
Electrical conductivity & $250,000 \mathrm{~cm}^{2} / \mathrm{V} \cdot \mathrm{s}$ \\
\hline Thermal conductivity & $5300 \mathrm{~W} / \mathrm{mK}$ \\
Specific surface area & $2630 \mathrm{~m}^{2} / \mathrm{g}$ \\
Optical transmittance & $97.7 \%$ \\
\hline
\end{tabular}

One of the most widely used graphene derivatives is graphene oxide. The structure of this nanomaterial consists in graphene sheets with stoppages of $\mathrm{sp}^{3}$ hybrid carbon atoms with functional groups such as hydroxyl and epoxy groups in the surface and carboxylic groups at the edges [39-41]. Therefore, GO presents higher hydrophilicity than G and it can be better dispersed in aqueous media. This feature favors the possibility of functionalization of graphene-like materials. The chemical reduction of these functional groups results in reduced graphene oxide, which presents a similar structure than G. rGO shows higher electrical conductivity compared to GO and is more hydrophobic due to the low content of functional groups [42,43]. Other graphene-based nanostructures are carbon nanotubes (CNTs). Single-walled CNTs are formed by graphene sheets that are rolled into a cylindrical arrangement [44-46]. If the CNTs are composed by several layers, a structure consisted in concentric cylinders is formed and is commonly called multi-walled CNTs (MWCNTs). 


\section{Thermoplastic Nanocomposites}

In this section we have summarized the recent publications on thermoplastic matrix composites modified by addition of graphene-derived nanofillers, modified graphene nanofillers or blends with other nanomaterials. These new nanocomposites have been obtained by extrusion, in most cases twin-screw extrusion, which can be followed by injection molding.

\subsection{Polypropylene Matrix Nanocomposites}

Table 2 shows that polypropylene (PP) matrix has been most commonly used [47-62] due to its availability and ease of processing. The effect of the concentration of nanofillers is a key parameter in the processing of nanocomposites. Iniesta et al. [47] added reduced graphene oxide in a range of concentrations between 0.05 and $1 \mathrm{wt}$. \%, using twin screw extrusion, to improve mechanical properties such as tensile strength and hardness with respect to PP. Nevertheless, the formation of agglomerates of rGO nanoparticles was observed. The effect of variable concentration of GnP added to PP has been described [48], finding an optimum concentration of $0.4 \mathrm{wt}$. \% for maximum mechanical resistance and a linear correlation between the melt shear viscosity and GNPs weight fraction was found. Extrusion processing of PP $+\mathrm{G}$ nanocomposites has been compared with surface coating and compression molding [49]. Graphene segregation took place under extrusion conditions; however, a continuous graphene network, with a percolation threshold of $0.4 \mathrm{wt}$. \% was obtained by compression molding, thus increasing electrical conductivity. In order to avoid agglomeration of the nanofiller, elongation flow processing for the dispersion of GO sheets in isotactic PP has been employed [50]. The more effective dispersion of the nanophases led to the increase of the thermal stability and mechanical properties of the nanocomposites with increasing GO content.

The effect of graphene nanoplatelets $(\mathrm{GnP})$ size on PP nanocomposites processed by twin-screw extrusion and injection molding has been studied [51] to find that smaller size nanofillers are the most effective in improving tensile strength and thermal stabilities, due to their lower tendency to agglomeration. These findings agree with computational studies [63]. On the other hand, large size nanofillers reduce the percolation threshold and increase electrical conductivity [52]. The role of large $\mathrm{GnP}$ as nucleating agents for PP crystallization has been also observed by Jun et al. [53] in extruded and injected nanocomposites. These observations are in agreement with the beneficial effect of large size GnP on the improvement of electrical conductivity but not on mechanical properties.

Recently, the combination of several nanofillers has demonstrated a useful strategy to obtain new nanocomposites with special properties. Synergy between graphene (G) and synthetic graphite (SG) was studied by Altay et al. [54], when added to PP matrix in a twin screw co-rotating extrusion machine. Mechanical properties and thermal stability were improved for high loads of G and SG. When GO is coated with short carbon fibers (SCF) [55], the extruded and injected PP-matrix nanocomposites showed higher thermal stability and mechanical resistance, which were attributed to the nucleating effect of GO-coated SCF for the crystallization of PP. Other researchers have combined graphene nanoplatelets $(\mathrm{GnP})$ with the addition of other additives to PP matrices, such as large mass percentages of magnesium oxide and hydroxide and ammonium phosphate [56]. The new quaternary nanocomposites combined combustion resistance with high thermal conductivity.

In any case, agglomeration is an impasse in the development of PP-based nanocomposites [57]. During extrusion, rupture and erosion provoke that large GnPs agglomerates tend to be exfoliated into smaller platelets. He et al. [58] determined that the residence time is a key parameter for a better dispersion of GnP. Only erosion mechanism thin layers can be exfoliated and by increasing the residence time in a twin-screw configuration, the homogeneity of the particle size distribution and the dispersibility of the nanophase are enhanced. The resulting nanocomposites present higher electrical and thermal conductivities. Re-extrusion also improves the dispersion of GnPs in PP matrices; however, the crystal phases of the thermoplastic material are affected [59]. Hopmann and Adamy [60] have recently proposed a two-stage process. A solvent is used in the first step, and then, graphene is predispersed by ultrasonication, before adding the dispersion to the twin-screw extruder, where the solvent is removed. The improved 
graphene dispersion leads to nanocomposite materials with up to $57 \%$ increase of the elongation at break. The effect of ultrasonication during twin screw compounding of PP + GnP nanocomposites has been compared with that on PP + carbon nanotubes and PP + carbon black nanocomposites [61]. The results showed that the size of the agglomerates can be reduced by ultrasonication for other carbon nanophases but not for PP + GnP, thus showing the difficulty of processing graphene nanocomposites. Functionalized graphene is an effective strategy to improve the dispersion of the nanophase in the polymeric matrix. Functional properties of PP such as flame retardancy (FR) have also been improved by addition of different forms of carbon nanoadditives. Hoffmann et al. [62] not only achieved this improvement in PP-FR modified by thermally reduced graphene oxide (TRGO) and multilayer graphene (MLG), but they have also described a remarkable (80\%) stiffness increase, combined with an increase of electrical conductivity. The best performance of TRGO is attributed to the presence of wrinkled functionalized graphene (FG) containing functional groups which enhance its dispersibility in the polymer matrix under extrusion conditions. The hydrophobicity of the nanophase can be tuned, and a better interaction with the polymer occurs during the melt extrusion process. Therefore, the electrical and mechanical properties of the nanocomposites are enhanced.

Table 2. Polypropylene-graphene nanocomposites melt-processed by extrusion.

\begin{tabular}{ccc}
\hline Matrix & Nanophase & Reference \\
\hline PP (Polypropylene) & Reduced graphene oxide (rGO) & {$[47]$} \\
\hline PP & GnP & {$[48,49,51-53,57-60]$} \\
\hline PP & GO & {$[50]$} \\
PP & GnP + SG (synthetic graphite) & {$[54]$} \\
PP & GO + short carbon fibers & {$[55]$} \\
PP & GnP, MgO and others & {$[56]$} \\
PP & GnP + carbon nanotubes + carbon black & {$[61]$} \\
\hline PP-FR (flame retardant & TRGO (thermally reduced GO) MLG & {$[62]$} \\
polypropylene) & (multilayer graphene) & \\
\hline
\end{tabular}

\subsection{Other Thermoplastic Matrices}

Although PP and PLA (see below) are the most widely studied matrices for graphene nanocomposites, many other thermoplastic materials have also been modified to obtain graphene nanocomposites (Table 3) [21,64-94].

Polyethylene (PE) and different types of polyethylene-derived materials such as linear low-density polyethylene (LLDPE), high density polyethylene (HDPE), or polyfluorinated ethylene propylene and polyethylene naphthalate (PEN) have been studied as matrices [64-69]. Reactive-melt extrusion of PE + $\mathrm{G}$ showed increasing crystallinity of the nanocomposites due to the nucleating effect of graphene. This increased not only mechanical properties but also the barrier to oxygen function of the polyolefin [64]. The mechanical tests on extruded and injected LLDPE-GO nanocomposites [65] showed an increase in tensile resistance, rigidity and hardness. In LLDPE-G nanocomposites, the effect of extrusion variables such as extruder and feeder speed has been studied $[66,67]$. One set of single-screw extrusion conditions was selected for HDPE [68], where the effect of graphene concentration, between 1 and 3 wt. \% was studied. Polymers with biomedical applications such as hybrid HDPE-ultrahigh molecular weight polyethylene (UHMWPE) [69] have been modified by amine surface functionalized GO, to improve not only elastic modulus and tensile strength, but also its resistance to biodegradation, thus making the new nanocomposite a possible candidate for bone tissue applications. Polyfluorinated ethylene propylene melt-spinning fibers [70] were reported to improve their chemical resistance by the addition of graphene in a low $(0.3 \mathrm{wt}$. \%) proportion. The inclusion of the fibers provokes an increase on the mechanical properties, reporting a Young's Modulus 19.5\% higher; and an improvement of the lipophilic behavior. Therefore, this kind of materials shows promising applications in oil-water separation. A modification of the conformation of PEN polymer chains due to graphene nanofiller has 
been described [71]. Consequently, the crystallization of PEN occurs with the addition of graphene at very low concentrations (0.01-0.1 wt. \%). The distribution and dispersion of the nanophase were more homogeneous, and a satisfactory intercalation of the graphene layers was found without the usage of additives or additional modifications of the nanophase. This was attributed to $\pi-\pi$ interactions between graphene platelets and naphthalene rings.

Polyamides (PA) are another commonly used base polymer for the processing of graphene containing nanocomposites [72-77]. PA6/PLA blends have been modified with variable GnP concentrations [72], achieving maximum thermal and mechanical resistance for the highest GnP ratio of 5 wt.\%. Few layers graphene (FLG) has been added to PA6/Poly (butylene terephthalate)-block-poly (tetramethylene glycol) (PBT-PTMG) to obtain ternary nanocomposites [73], using both in situ polymerization and extrusion. By this method, a low FLG concentration of $0.5 \mathrm{wt}$ \% was sufficient to increase impact, flexural strength and elongation at break. A different method, consisting of masterbatch dilution was employed by Rashmi et al. [74] to obtain PA11/GnP materials, with enhanced mechanical properties for $5 \mathrm{wt}$ \% GnP content. An acceleration of the crystallization process of PA in the presence of $\mathrm{G}$ has been described for nanocomposites extruded under the same conditions as the unmodified polymer [75]. The functionalization of graphene has been proved to enhance the dispersibility into the PA matrix through reactive extrusion [76].

Other widely used thermoplastics include polystyrene (PS), thermoplastic polyurethane (TPU) or poly (methylmethacrylate) (PMMA) matrices [21,78,79]. Ionic liquids have been utilized to modify the surface of the nanophase aiming at better dispersibility in the polymeric matrix. In this case, the dispersion of IL-modified graphene resulted in a better dispersion of the nanophase. The obtained nanocomposites showed higher mechanical and electrical properties [78] (see Figure 2) and better processability [21]. Low concentrations of GO are used in PMMA matrices in presence of 1 wt. $\%$ TiO 2 processed by using twin-screw extrusion [79] with potential dental applications. PA/PP composites [80] have been modified by functionalized GO, finding that GO concentrations should be maintained lower than $1 \mathrm{wt}$ \% in order to maximize mechanical resistance. Liquid-phase feeding (LPF), and solid-solid deposition (SSD) have been proposed by Muñoz et al. [81] to reduce agglomeration of GO in order to scale the commercial processing of PS nanocomposites [82]. ABS (acrylonitrile butadiene styrene) has been reinforced by rGO [83], multi-walled carbon nanotubes or both nanofillers [84]. It has been proved that the addition of these nanophases also affects the rheological properties of the nanocomposites, increasing the elastic behavior with a reduction of the ductility. On the other hand, $\mathrm{GnP}$ have been used as additive in poly(carbonate) (PC) and PC-ABS blends [85,86], increasing the mechanical properties of the nanocomposite but without the loss of ductility and an improvement on the thermal stability. Reactive extrusion is utilized to prepare conductive nanocomposites composed by poly(butylenetherephtale) (PBT) with several graphenic materials [87].
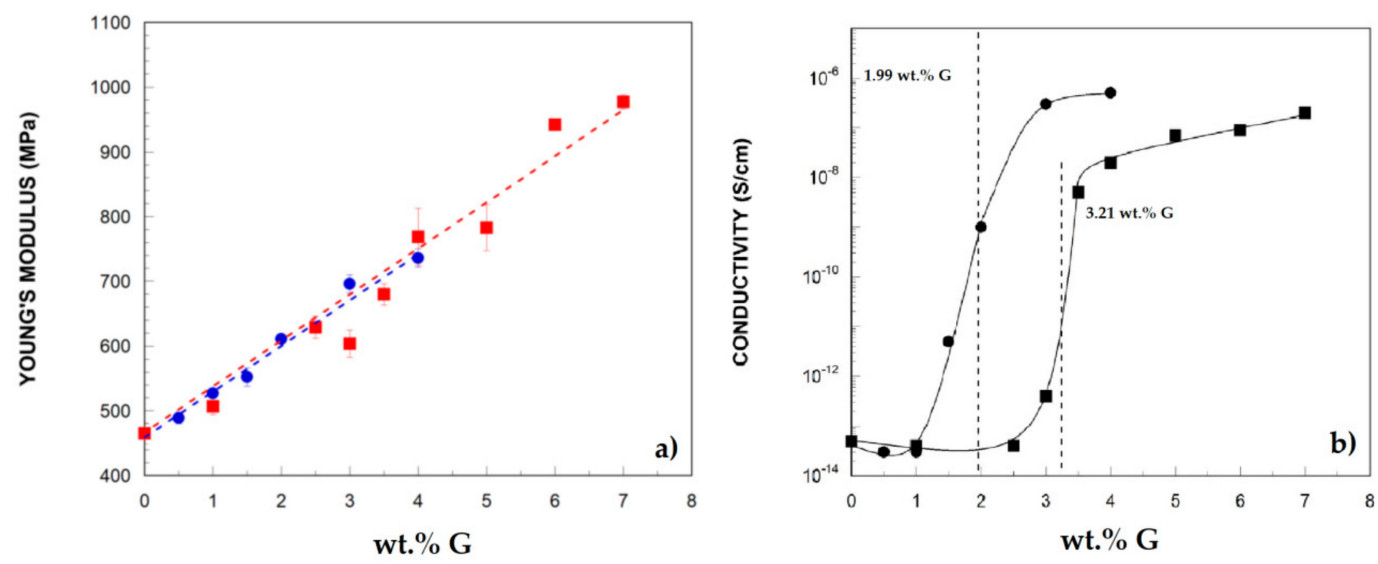

Figure 2. Increase of Young's Modulus (a) and conductivity (b) of thermoplastic polyurethane (TPU) -based nanocomposites with the addition of graphene [78]. 
Table 3. Thermoplastic graphene nanocomposites melt-processed by extrusion.

\begin{tabular}{|c|c|c|}
\hline Matrix & Nanophase & Reference \\
\hline PE (Polyethylene) & Graphene & [67] \\
\hline LLDPE (Linear low density Polyethylene) & GO & {$[65]$} \\
\hline LLDPE & $\mathrm{GnP}$ & {$[66,67]$} \\
\hline HDPE & $\mathrm{GnP}$ & {$[68]$} \\
\hline $\begin{array}{l}\text { HDPE/UHMWPE (High density polyethylene/Ultrahigh } \\
\text { molecular weight polyethylene) }\end{array}$ & GO & [69] \\
\hline FEP (polyfluorinated ethylene-propylene) & Graphene & [70] \\
\hline PEN (Polyethylene naphthalate) & GnP & [71] \\
\hline PA6 (Polyamide 6) & $\mathrm{GnP}$ & [72] \\
\hline PA6 & Graphene + PBT-PTMG & [73] \\
\hline PA11 (Polyamide 11) & $\mathrm{GnP}$ & [74] \\
\hline PA & Graphene & [75] \\
\hline PA6 & $\begin{array}{l}\text { Functionalized } \\
\text { Graphene }\end{array}$ & [76] \\
\hline PA & GO & [77] \\
\hline TPU (Thermoplastic Polyurethane) & $\begin{array}{l}\text { Graphene Graphene } \\
\text { modified by ionic liquid }\end{array}$ & [78] \\
\hline PMMA & $\begin{array}{c}\text { GO } \\
\text { GO modified by ionic } \\
\text { liquid }\end{array}$ & [21] \\
\hline PMMA (Polymethylmethacrylate) & $\mathrm{GO}+\mathrm{TiO}_{2}$ & [79] \\
\hline $\mathrm{PA} / \mathrm{PP}$ & $\mathrm{GO}$ & [80] \\
\hline PS (Polystyrene) & \multirow{2}{*}{ GO } & \multirow{2}{*}[81]{} \\
\hline PBAT (Poly(3-hydroxybutyrate- co-3-hydroxyvalerate) & & \\
\hline PS & Graphene & {$[82]$} \\
\hline ABS (Acrylonitrile butadiene styrene) & rGO and/or MWCNT & {$[83,84]$} \\
\hline PC-ABS Polycarbonate-(acrylonitrile butadiene styrene) & $\begin{array}{l}\text { Graphene nanoplatelets } \\
(\mathrm{GnP})\end{array}$ & [85] \\
\hline PC (Polycarbonate) & $\mathrm{GnP}$ & [86] \\
\hline PBT (Poly (butylenetherephtalate) & $\mathrm{GnP}, \mathrm{GO}$ and $\mathrm{rGO}$ & [87] \\
\hline PSU (Polysulfone) & rGO & [88] \\
\hline PPS (Polyphenylene sulfide) & $\mathrm{GnP}$ & {$[90]$} \\
\hline PVDF (Polyvinylidene fluoride) & GO & {$[91,92]$} \\
\hline PEEK (Polyether ketone) & $\begin{array}{l}\text { Modified } \mathrm{GO}+ \\
\text { modified } \mathrm{SiO}_{2}\end{array}$ & [93] \\
\hline PEEK & $\mathrm{GnP}$ & [94] \\
\hline
\end{tabular}

Highly thermal, chemical and mechanical resistant polymers such as PSU (Polysulfone) [88], PPS (Polyphenylene sulfide) [89,90], PVDF (Polyvinylidene fluoride) [91,92] and PEEK (Polyether ketone) $[93,94]$ have also been modified by rGO, GnP, GO or a combination of modified GO and modified $\mathrm{SiO}_{2}$. For example, the surface modification of graphene with PSU brushes increased the affinity of the nanophase with the thermoplastic matrix, resulting in the improvement of the nanophase dispersion. In the case of PVDF-GO composites, the addition of the nanophase leads to higher values of thermal and electrical conductivities. PEEK-based nanocomposites present an enhanced tribological performance, higher mechanical properties and improved electrical conductivity.

\subsection{Biodegradable and Biocompatible Polymers}

In the last century, plastics have become an integral part of our daily lives due to their excellent properties, such as density, mechanical properties, processability and price. However, plastic 
waste has changed into one of the most challenging problems in our society. The plastic waste production has been estimated in over 6 billion tons [95]. Currently, the production of plastic waste is approximately 300 million tons every year worldwide and only 10\% of this waste is recycled [96,97]. Polylactic acid (PLA) is one of the most extensively used materials in functional products, as it is a biodegradable, non-contaminant material, exhibiting good mechanical properties that are frequently used in aerospace, automotive and biomedical engineering applications [98,99]. Therefore, the recent interest in the development of biodegradable materials has attracted increasing attention towards PLA nanocomposites [100]. Table 4 summarizes the very last PLA-graphenic composites prepared by means of melt blending [101-111] and other biodegradable and biocompatible polymers [112-117].

The versatility of extrusion processing is an advantage for the control of the microstructure. Thus, multilayer co-extrusion is used to orient graphene and obtain a layered material with alternating PLA and PLA + GnP layers [102]. In situ polycondensation of lactic acid has been used to obtain a masterbatch containing exfoliated graphene before melt extrusion of PLA and diluted masterbatch nanocomposite strips [103]. PLA-masterbatch with $0.05 \mathrm{wt}$. \% graphene showed the best dispersion and mechanical properties. For recyclable materials, it is necessary to study the effect of reprocessing on their structure and properties. Interestingly, it has been described [104] that GnP decrease the degradation of PLA under repeated processing, using, in this case, a single screw extruder. Multiple extrusion cycles improved the dispersion of $\mathrm{GnP}$ in the polymer matrix, reducing the size of the aggregates (see Figure 3). In contrast, hydrolytic degradation of PLA under immersion conditions in a solution of $\mathrm{NaOH}$ was faster for PLA nanocomposites containing different nanophases, including graphene, than that of neat PLA [105].
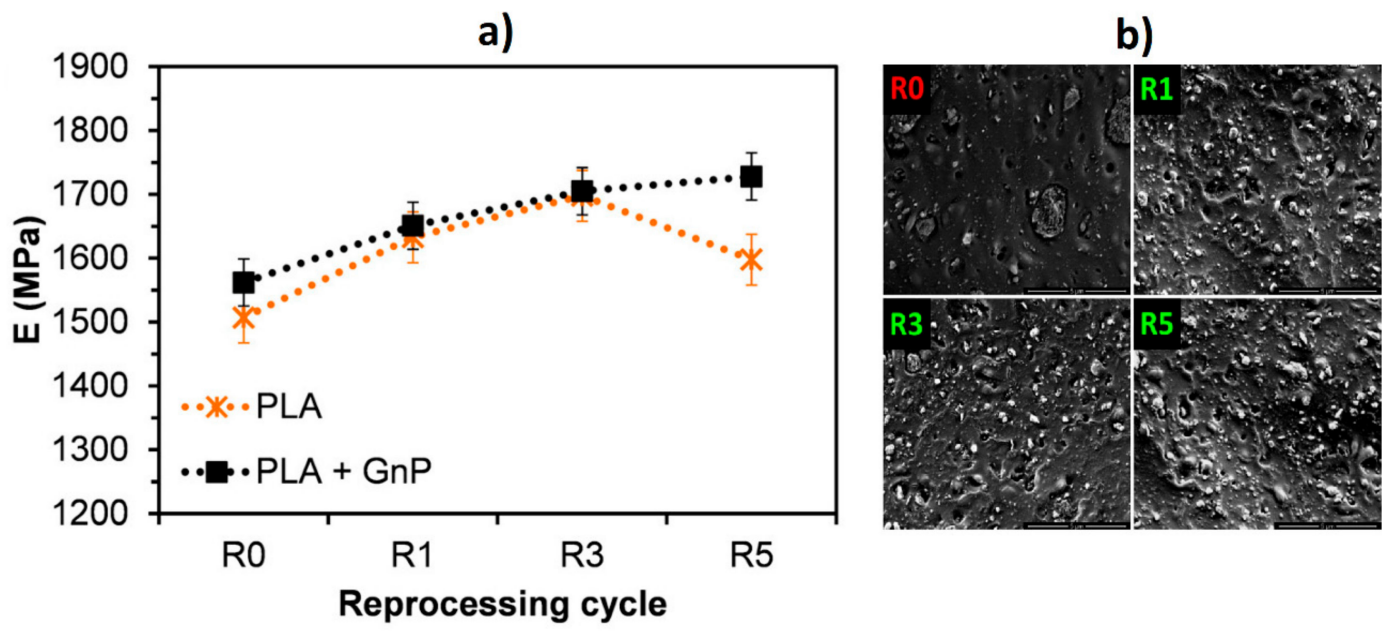

Figure 3. Variation of Young's Modulus of polylactic acid (PLA) and PLA + graphene nanoplatelet $(\mathrm{GnP})$ with the reprocessing cycles (a) and dispersion of GnP in the matrix (b) [104].

The effect of the different types of nanofillers (graphene and graphene-CNTs blends) of PLA has been explored [108-110]. It has been found that the crystallinity of the nanocomposite was increased with the nanotube-containing. Extruded PLA films with $6 \mathrm{wt}$. \% proportion of mixed GnP + carbon nanotube fillers incorporated by solution blending have been recently described [108]. The nanofillers were found to affect crystallinity, but the final properties of the materials depend on processing and ageing conditions. Increased crystallinity by combination of $\mathrm{GnP}$ and multiwalled carbon nanotubes has also been reported [109] for PLA. The reinforcing effect of the nanophases was confirmed by dynamic mechanical analysis (DMA). The functionalization of GO improves dispersion and increases crystallinity, thermal and mechanical properties, as it is discussed above with other thermoplastic matrices. A reactive extrusion method was employed to obtain PLA nanocomposite containing amidated graphene oxide [110]. 
Biodegradable nanocomposites have been obtained by different approaches, such as thermal reduction of GO during processing of PLA-PBS (polybutylene succinate)-rGO nanocomposites [111], and the uniform coating of PLA with graphene [106]. In this later case, not only the mechanical properties are improved but also the hydrophobicity of PLA. This is a relevant issue, as the affinity of PLA towards water is one of the major drawbacks in the use of this biodegradable matrix. Reactive blending of PLA with thermoplastic starch and GnP has been achieved by extrusion, and films were then obtained using cast-film extrusion [112]. In this case, the addition of GnP produces $900 \%$ toughness increase. A crack-bridging mechanism was proposed for the enhancement of mechanical properties, attributed to the high aspect ratio of the nanofiller.

Table 4. Biocompatible and biodegradable graphene nanocomposites melt-processed by extrusion.

\begin{tabular}{ccc}
\hline Matrix & Nanophase & Reference \\
\hline PLA Poly(lactic acid) & Graphene & {$[101-103,105,106]$} \\
PLA & GnP & {$[104]$} \\
PLA & GnP + CNT & {$[107-109]$} \\
PLA & Amidated graphene oxide & {$[110]$} \\
\hline PLA/PBS (Polylactic acid/polybutylene succinate) & GO & {$[111]$} \\
\hline Thermoplastic starch/PLA & Graphene & {$[112,113]$} \\
\hline PHB (Poly3-hydroxybutyrate-co-3-hydroxybutyrate) & GnP + A-fnSiO & {$[114]$} \\
\hline PHB & GO Hydrophobically & {$[115]$} \\
\hline PBS & modified GO & {$[116]$} \\
\hline PHBV (Poly3-hydroxybutyrate-co-3-hydroxyvalerate) & GnP + Biocarbon & {$[117]$} \\
\hline
\end{tabular}

In the case of the biodegradable and biocompatible plastics, different mixtures of graphene and other materials are used as fillers to preserve the sustainability of the composites. Manufacturing of biodegradable plastics can reduce the environmental impact and favor renewable resources. However, some properties of biodegradable polymers cannot often be comparable with petroleum-based plastics and the addition of fillers may enhance the physical, chemical and mechanical properties $[114,115]$. Biocarbon and GnP have been successfully incorporated to bio-based PBS (Poly (butylensucciante)), showing an exceptional increase of the mechanical properties when the dilution of the masterbatch is used instead of direct compounding method [116]. For PHBV (Poly (3-hydroxybutyrate-co-3-hydroxyvalerate)), the selected fillers are a combination of $\mathrm{rGO}$ and $\mathrm{ZnO}$ nanoparticles [117], to maintain the environmentally friendly characteristics of the base polymer.

\section{Conclusions and Future Outlook}

The present work is an overview on very recent developments in the field of graphenethermoplastic nanocomposites melt processed by extrusion methods. A wide range of matrices have been studied, from commodity polymers to high resistant engineering polymers. Special attention is being paid at the development of biodegradable and biocompatible nanocomposites.

Extrusion is readily scalable to industrial manufacturing of final products; however, in most cases, obtaining homogeneous graphene dispersions within the polymer matrix is not a simple task. Segregation and agglomeration of the nanophases are responsible for the lack of improvement in the thermal, mechanical and electrical properties with respect to the unmodified matrix materials.

The results of this review denote that the most widely used techniques to improve the dispersion of graphenic nanofillers are sonication, surface modification and the application of a coating layer of graphene on the polymer surface. However, another promising technique that is beginning to yield positive results is the use of ionic liquids, which should be explored more thoroughly. Other strategies 
are focused on the modification of the extrusion process, the use of masterbatches and the combination of graphene with other materials as hybrid nanophases.

The main factors that affect the characteristics and attributes of these nanocomposites are the nanofiller size and concentration. It has been stated that larger sizes of nanofillers result in a reduction of the mechanical properties but an increase of other functional properties, such as electrical conductivity. However, the effect of graphene concentration is not so well defined, and more studies are necessary.

A relevant field, which has received limited consideration until the present moment, is that of the influence of the additives on the deformation and fracture modes and on the resistance to degradation of the final materials.

Finally, another line of work that is starting to receive attention is the tribological performance of extruded nanocomposites as a function of extrusion parameters, polymer structure, nanofiller orientation and surface modification.

Author Contributions: Conceptualization, J.S., C.S., R.P., M.-D.A. and M.-D.B.; methodology, J.S., C.S., R.P., M.-D.A. and M.-D.B.; validation, J.S., C.S., R.P., M.-D.A. and M.-D.B.; formal analysis, J.S., C.S., R.P., M.-D.A. and M.-D.B.; investigation, J.S., C.S., R.P., M.-D.A. and M.-D.B.; resources, J.S., C.S., R.P., M.-D.A. and M.-D.B.; writing-original draft preparation, J.S., C.S., R.P., M.-D.A. and M.-D.B.; writing-review and editing, J.S., C.S., R.P., M.-D.A. and M.-D.B.; visualization, J.S., C.S., R.P., M.-D.A. and M.-D.B.; supervision, J.S., C.S., R.P., M.-D.A. and M.-D.B.; project administration, J.S., C.S., R.P., M.-D.A. and M.-D.B.; funding acquisition, J.S. and M.-D.B. All authors have read and agreed to the published version of the manuscript.

Funding: This research was funded by Ministerio de Economia, Industria y Competitividad, Agencia Estatal de Investigacion (MINECO and AEI, Spain), the EU FEDER Program (Grant \# MAT2017-85130-P). “Este trabajo es resultado de la actividad desarrollada en el marco del Programa de Ayudas a Grupos de Excelencia de la Region de Murcia, de la Fundacion Seneca, Agencia de Ciencia y Tecnologia de la Region de Murcia (Grant \#19877/GERM/15)". C. Sánchez is grateful to Ministerio de Ciencia, Innovación y Universidades and AEI (Spain) for research grant \#PRE2018-083774.

Conflicts of Interest: The authors declare no conflict of interest. The funders had no role in the design of the study; in the collection, analyses or interpretation of data; in the writing of the manuscript or in the decision to publish the results.

\section{References}

1. Sun, J.; Wang, C.; Shen, T.; Song, H.; Li, D.; Zhao, R.; Wang, X. Engineering the Dimensional Interface of BiVO4-2D Reduced Graphene Oxide (RGO) Nanocomposite for Enhanced Visible Light Photocatalytic Performance. Nanomaterials 2019, 9, 907. [CrossRef] [PubMed]

2. Young, R.J.; Kinloch, I.A.; Gong, L.; Novoselov, K.S. The mechanics of graphene nanocomposites: A review. Compos. Sci. Technol. 2012, 72, 1459-1476. [CrossRef]

3. Hu, K.; Kulkarni, D.D.; Choi, I.; Tsukruk, V.V. Graphene-polymer nanocomposites for structural and functional applications. Prog. Polym. Sci. 2014, 39, 1934-1972. [CrossRef]

4. Nguyen, S.T.; Ruoff, R.S. Graphene-based composite materials. Nature 2006, 442, 282-286.

5. Huang, X.; Qi, X.; Boey, F.; Zhang, H. Graphene-based composites. Chem. Soc. Rev. 2012, 41, 666-686. [CrossRef]

6. Mohan, V.B.; Lau, K.-t.; Hui, D.; Bhattacharyya, D. Graphene based materials and their composites: A review on production, applications and products limitations. Compos. B Eng. 2018, 142, 200-220. [CrossRef]

7. Maas, M. Carbon Nanomaterials as Antibacterial Colloids. Materials 2016, 9, 617. [CrossRef]

8. Liao, C.; Li, Y.; Tjong, S.C. Antibacterial Activities of Aliphatic Polyester Nanocomposites with Silver Nanoparticles and/or Graphene Oxide Sheets. Nanomaterials 2019, 9, 1102. [CrossRef]

9. Silva, M.; Alves, N.M.; Paiva, M.C. Graphene-polymer nanocomposites for biomedical application. Polym. Adv. Technol. 2018, 29, 687-700. [CrossRef]

10. Ratinac, K.R.; Gilbert, R.G.; Ye, L.; Jones, A.S.; Ringer, S.P. The effects of processing and organoclay properties on the structure of poly(methyl methacrylate)-clay nanocomposites. Polymer 2016, 47, 6337-6361. [CrossRef]

11. Vergnes, B. Influence of Processing Conditions on the Preparation of Clay-Based Nanocomposites by Twin-Screw Extrusion. Int. Polym. Process. 2019, 34, 482-501. [CrossRef]

12. Novoselov, K.S.; Geim, A.K.; Jiang, D.; Zhang, Y.; Dubonos, S.V.; Grugorieva, I.V.; Firsov, A.A. Electric field effect in atomically thin carbon films. Science 2004, 306, 666-669. [CrossRef] [PubMed] 
13. Bianco, A.; Cheng, H.M.; Enoki, T.; Gogotsi, Y.; Hurt, R.H.; Koratkar, N.; Kyotani, T.; Monthioux, M.; Park, C.R.; Tascon, J.M.; et al. All in the graphene family-A recommended nomenclature for two-dimensional carbon materials. Carbon 2013, 65, 1-6. [CrossRef]

14. Johnson, D.W.; Dobson, B.P.; Coleman, K.S. A manufacturing perspective on graphene dispersions. Curr. Opin. Colloid Interface Sci. 2015, 20, 367-382. [CrossRef]

15. Yang, J.; Pruvost, S.; Livi, S.; Duchet-Rumeau, J. The Role of Fluorinated IL as an Interfacial Agent in P(VDF-CTFE)/Graphene Composite Films. Nanomaterials 2019, 9, 1181. [CrossRef]

16. Wang, J.; Wu, J.; Xu, W.; Zhang, Q.; Fu, Q. Preparation of poly (vinylidene fluoride) films with excellent electric property, improved dielectric property and dominant polar crystalline forms by adding a quaternary phosphorus salt functionalized graphene. Compos. Sci. Technol. 2014, 91, 1-7. [CrossRef]

17. Zheng, X.; Yu, H.; Yue, S.; Xing, R.; Zhang, Q.; Liu, Y.; Zhang, B. Functionalization of graphene and dielectric property relationships in PVDF/graphene nanosheets composites. Int. J. Electrochem. Sci. 2018, 13, 1-13. [CrossRef]

18. Divakaran, N.; Zhang, X.; Kale, M.B.; Senthil, T.; Mubarak, S.; Dhamodharan, D.; Wu, L.X.; Wang, J.L. Fabrication of surface modified graphene oxide/unsaturated polyester nanocomposites via in-situ polymerization: Comprehensive property enhancement. Appl. Surf. Sci. 2020, 502, 144164. [CrossRef]

19. Bose, S.; Kuila, T.; Uddin, M.E.; Kim, N.H.; Lau, A.K.T.; Lee, J.H. In-situ synthesis and characterization of electrically conductive polypyrrole/graphene nanocomposites. Polymer 2010, 51, 5921-5928. [CrossRef]

20. Steurer, P.; Wissert, R.; Thomann, R.; Mulhaupt, R. Functionalized Graphenes and Thermoplastic Nanocomposites Based upon Expanded Graphite Oxide. Macromol. Rapid Commun. 2006, 30, 316-327. [CrossRef]

21. Sanes, J.; Ojados, G.; Pamies, R.; Bermúdez, M.D. PMMA nanocomposites with graphene oxide hybrid nanofillers. Express Polym. Lett. 2019, 13, 910-922. [CrossRef]

22. Fourati, Y.; Magnin, A.; Putaux, J.-L.; Boufi, S. One-step processing of plasticized starch/cellulose nanofibrils nanocomposites via twin-screw extrusion of starch and cellulose fibers. Carbohydr. Polym. 2020, 229, 115554. [CrossRef] [PubMed]

23. Kim, H.; Macosko, C.W. Processing-property relationship of polycarbonate/graphene composites. Polymer 2009, 50, 3797-3809. [CrossRef]

24. Murariu, M.; Dechief, A.L.; Bonnaud, L.; Paint, Y.; Gallos, A.; Fontaine, G.; Bourbigot, S.; Dubois, P. The production and properties of polylactide composites filled with expanded graphite. Polym. Degrad. Stab. 2010, 95, 889-900. [CrossRef]

25. Hassouna, F.; Laachachi, A.; Chapron, D.; El Mouedden, Y.; Toniazzo, V.; Ruch, D. Development of new approach based on Raman spectroscopy to study the dispersion of expanded graphite in poly(lactide). Polym. Degrad. Stab. 2011, 96, 2040-2047. [CrossRef]

26. Idowu, A.; Boesl, B.; Agarwal, A. 3D graphene foam-reinforced polymer composites. A review. Carbon 2018, 135, 52-71. [CrossRef]

27. Zhang, Y.B.; Small, J.P.; Pontius, W.V.; Kim, P. Fabrication and electric-field-dependent transport measurements of mesoscopic graphite devices. Appl. Phys. Lett. 2005, 86, 073104. [CrossRef]

28. Potts, J.R.; Dreyer, D.R.; Bielawski, C.W.; Ruoff, R.S. Graphene-based polymer nanocomposites. Polymer 2011, 52, 5-25. [CrossRef]

29. Papageorgiou, D.G.; Kinloch, I.A.; Young, R.J. Mechanical properties of graphene and graphene-based nanocomposites. Prog. Mater. Sci. 2017, 90, 75-127. [CrossRef]

30. Zindani, D.; Kumar, K. Graphene-based polymeric nano-composites: An introspection into functionalization, processing techniques and biomedical applications. Biointerface Res. Appl. Chem. 2019, 9, 3926-3933.

31. Panwar, N.; Soehartono, A.M.; Chan, K.K.; Zeng, S.; Xu, G.; Qu, J.; Coquet, P.; Yong, K.T.; Chen, X. Nanocarbons for biology and medicine: Sensing, imaging, and drug delivery. Chem. Rev. 2019, 119, 9559-9656. [CrossRef] [PubMed]

32. Ioniţă, M.; Vlăsceanu, G.M.; Watzlawek, A.A.; Voicu, S.I.; Burns, J.S.; Iovu, H. Graphene and functionalized graphene: Extraordinary prospects for nanobiocomposite materials. Compos. Part B Eng. 2017, 121, 34-57. [CrossRef]

33. Phiri, J.; Gane, P.; Maloney, T.C. General overview of graphene: Production, properties and application in polymer composites. Mater. Sci. Eng. B 2017, 215, 9-28. [CrossRef] 
34. Yang, G.; Li, L.; Lee, W.B.; Ng, M.C. Structure of graphene and its disorders: A review. Sci. Technol. Adv. Mater. 2018, 19, 613-648. [CrossRef]

35. Ramírez, C.; Figueiredo, F.M.; Miranzo, P.; Poza, P.; Osendi, M.I. Graphene nanoplatelet/silicon nitride composites with high electrical conductivity. Carbon 2012, 50, 3607-3615. [CrossRef]

36. Zhu, Y.W.; Murali, S.; Cai, W.W.; Li, X.S.; Suk, J.W.; Potts, J.R.; Ruoff, R.S. Graphene and Graphene Oxide: Synthesis, Properties, and Applications. Adv. Mater. 2010, 22, 3906-3924. [CrossRef] [PubMed]

37. Rao, C.N.R.; Matte, H.S.S.R.; Subrahmanyam, K.S. Synthesis and Selected Properties of Graphene and Graphene Mimics. Acc. Chem. Res. 2013, 46, 149-159. [CrossRef]

38. Plachá, D.; Jampilek, J. Graphenic Materials for Biomedical Applications. Nanomaterials 2019, 9, 1758. [CrossRef]

39. Lawal, A.T. Graphene-based nano composites and their applications. A review. Biosens. Bioelectron. 2019, 141, 111384. [CrossRef]

40. Xia, M.Y.; Xie, Y.; Yu, C.H.; Chen, G.Y.; Li, Y.H.; Zhang, T.; Peng, Q. Graphene-based nanomaterials: The promising active agents for antibiotics-independent antibacterial applications. J. Control. Release 2019, 307, 16-31. [CrossRef]

41. De Melo-Diogo, D.; Lima-Sousa, R.; Alves, C.G.; Correia, I.J. Graphene family nanomaterials for application in cancer combination photothermal therapy. Biomater. Sci. 2019, 7, 3534-3551. [CrossRef]

42. Chakraborty, M.; Hashmi, M.S.J. Wonder material graphene: Properties, synthesis and practical applications. Adv. Mater. Process. Technol. 2018, 4, 573-602. [CrossRef]

43. Taniselass, S.; Arshad, M.K.M.; Gopinath, S.C.B. Graphene-based electrochemical biosensors for monitoring noncommunicable disease biomarkers. Biosens. Bioelectron. 2019, 130, 276-292. [CrossRef]

44. Eivazzadeh-Keihan, R.; Maleki, A.; de la Guardia, M.; Bani, M.S.; Chenab, K.K.; Pashazadeh-Panahi, P.; Baradaran, B.; Mokhtarzadeh, A.; Hamblin, M.R. Carbon based nanomaterials for tissue engineering of bone: Building new bone on small black scaffolds: A review. J. Adv. Res. 2019, 18, 185-201. [CrossRef] [PubMed]

45. Li, Z.; Wang, L.; Li, Y.; Feng, Y.; Feng, W. Carbon-based functional nanomaterials: Preparation, properties and applications. Compos. Sci. Technol. 2019, 179, 10-40. [CrossRef]

46. Setaro, A. Advanced carbon nanotubes functionalization. J. Phys. Condens. Matter 2017, 29, 11-14. [CrossRef]

47. Iniesta-Galindo, M.G.; Perez-Gonzalez, J.; Marin-Santibanez, B.M.; Balmori-Ramirez, H. Preparation at large-scale of polypropylene nanocomposites with microwaves reduced graphene oxide. Mater. Res. Express 2019, 6, 105347. [CrossRef]

48. Liang, J.Z.; Du, Q. Melt Flow and Flexural Properties of Polypropylene Composites Reinforced with Graphene Nano-Platelets. Int. Polym. Process. 2018, 33, 35-41. [CrossRef]

49. Al Imran, K.; Lou, J.Z.; Shivakumar, K.N. Enhancement of electrical and thermal conductivity of polypropylene by graphene nanoplatelets. J. Appl. Polym. Sci. 2018, 135, 45833. [CrossRef]

50. Qiu, F.; Yin, X.C.; Qu, J.P. Formation of polypropylene/functional graphene oxide nanocomposites with Different FGs loading in elongation flow condition. Polym. Eng. Sci. 2019, 59, 830-837. [CrossRef]

51. Jun, Y.S.; Um, J.G.; Jiang, G.; Yu, A. A study on the effects of graphene nano-platelets (GnPs) sheet sizes from a few to hundred microns on the thermal, mechanical, and electrical properties of polypropylene (PP)/GnPs composites. Express Polym. Lett. 2018, 12, 885-897. [CrossRef]

52. He, S.H.; Zhang, J.J.; Xiao, X.T.; Hong, X.M.; Lai, Y.J. Investigation of the conductive network formation of polypropylene/graphene nanoplatelets composites for different platelet sizes. J. Mater. Sci. 2017, 52, 13103-13119. [CrossRef]

53. Jun, Y.S.; Um, J.G.; Jiang, G.P.; Lui, G.; Yu, A.P. Ultra-large sized graphene nano-platelets (GnPs) incorporated polypropylene (PP)/GnPs composites engineered by melt compounding and its thermal, mechanical, and electrical properties. Compos. Part B Eng. 2018, 133, 218-225. [CrossRef]

54. Altay, L.; Atagur, M.; Sever, K.; Sen, I.; Uysalman, T.; Seki, Y.; Sarikanat, M. Synergistic effects of graphene nanoplatelets in thermally conductive synthetic graphite filled polypropylene composite. Polym. Compos. 2019, 40, 277-287. [CrossRef]

55. Wang, C.C.; Zhao, Y.Y.; Ge, H.Y.; Qian, R.S. Enhanced Mechanical and Thermal Properties of Short Carbon Fiber Reinforced Polypropylene Composites by Graphene Oxide. Polym. Compos. 2018, 39, 405-413. [CrossRef] 
56. Idumah, C.I.; Hassan, A.; Bourbigot, S. Synergistic effect of exfoliated graphene nanoplatelets and non-halogen flame retardants on flame retardancy and thermal properties of kenaf flour-PP nanocomposites. J. Therm. Anal. Calorim. 2018, 134, 1681-1703. [CrossRef]

57. Rodrigues, P.; Santos, R.M.; Paiva, M.C.; Covas, J.A. Development of Dispersion during Compounding and Extrusion of Polypropylene/Graphite Nanoplates Composites. Int. Polym. Process. 2017, 32, 614-622. [CrossRef]

58. He, S.H.; Zhang, J.J.; Xiao, X.T.; Lai, Y.J.; Chen, A.F.; Zhang, Z.R. Study on the morphology development and dispersion mechanism of polypropylene/graphene nanoplatelets composites for different shear field. Comp. Sci. Technol. 2017, 153, 209-221. [CrossRef]

59. Triantou, M.; Todorova, N.; Giannakopoulou, T.; Vaimakis, T.; Trapalis, C. Mechanical performance of re-extruded and aged graphene/polypropylene nanocomposites. Polym. Int. 2017, 66, 1716-1724. [CrossRef]

60. Hopmann, C.; Adamy, M. Preparation of graphene-based compounds with improved dispersion by a two-stage production process. J. Polym. Eng. 2019, 39, 368-376. [CrossRef]

61. Zhong, J.; Isayev, A.I.; Zhang, X.P. Ultrasonic twin screw compounding of polypropylene with carbon nanotubes, graphene nanoplates and carbon black. Eur. Polym. J. 2016, 80, 16-39. [CrossRef]

62. Hofmann, D.; Wartig, K.A.; Thomann, R.; Dittrich, B.; Schartel, B.; Mulhaupt, R. Functionalized Graphene and Carbon Materials as Additives for Melt-Extruded Flame Retardant Polypropylene. Macromol. Mater. Eng. 2013, 298, 1322-1334. [CrossRef]

63. Xu, Z.W.; He, S.H.; Zhang, J.J.; Huang, S.J.; Chen, A.F.; Fu, X.L.; Zhang, P. Relationship between the structure and thermal properties of polypropylene/graphene nanoplatelets composites for different platelet-sizes. Compos. Sci. Technol. 2019, 183, 107826. [CrossRef]

64. Wang, B.; Peng, D.; Lv, R.H.; Na, B.; Liu, H.S.; Yu, Z. Generic melt compounding strategy using reactive graphene towards high performance polyethylene/graphene nanocomposites. Compos. Sci. Technol. 2019, 177, 1-9. [CrossRef]

65. Li, J.T.; Gunister, E.; Barsoum, I. Effect of graphene oxide as a filler material on the mechanical properties of LLDPE nanocomposites. J. Compos. Mater. 2019, 53, 2761-2773. [CrossRef]

66. Khanam, P.N.; AlMaadeed, M.A.; Ouederni, M.; Harkin-Jones, E.; Mayoral, B.; Hamilton, A.; Sun, D. Melt processing and properties of linear low density polyethylene-graphene nanoplatelet composites. Vacuum 2016, 130, 63-71. [CrossRef]

67. Gaska, K.; Xu, X.D.; Gubanski, S.; Kadar, R. Electrical, Mechanical, and Thermal Properties of LDPE Graphene Nanoplatelets Composites Produced by Means of Melt Extrusion Process. Polymers 2017, 9, 11. [CrossRef] [PubMed]

68. Seretis, G.V.; Manolakos, D.E.; Provatidis, C.G. On the graphene nanoplatelets reinforcement of extruded high density polyethylene. Compos. Part B Eng. 2018, 145, 81-89. [CrossRef]

69. Bhusari, S.A.; Sharma, V.; Bose, S.; Basu, B. HDPE/UHMWPE hybrid nanocomposites with surface functionalized graphene oxide towards improved strength and cytocompatibility. J. R. Soc. Interface 2019, 16, 20180273. [CrossRef] [PubMed]

70. Pan, J.F.; Xiao, C.F.; Huang, Y.; Zhu, Z.T. Preparation and properties of melt-spun poly(fluorinated ethylene-propylene)/graphene composite fibers. Polym. Compos. 2020, 41, 233-243. [CrossRef]

71. Espinoza-Martinez, A.B.; Avalos-Belmontes, F.; Ramos-de Valle, L.F.; Espinoza-Martinez, P.A.; Avila-Orta, C.A.; Soriano-Corral, F.; Mata-Padilla, J.M.; Tellez-Rosas, M.M. Morphological Study and Dielectric Behavior of Nonisothermally Crystallized Poly(ethylene naphthalate) Nanocomposites as a Function of Graphene Content. J. Nanomater. 2016, 14, 9846102. [CrossRef]

72. Bijarimi, M.; Amirul, M.; Norazmi, M.; Ramli, A.; Desa, M.S.Z.; Desa, M.D.A.; Abu Samah, M.A. Preparation and characterization of poly (lactic acid) (PLA)/polyamide 6 (PA6)/graphene nanoplatelet (GNP) blends bio-based nanocomposites. Mater. Res. Express. 2019, 6, 055044. [CrossRef]

73. Fu, X.B.; Dong, X.; Liu, Y.; Zhao, X.K.; Zhang, N.; Qi, S.X.; Wang, D.J.; Yang, G.S. Combined graphene and poly (butylene terephthalate)-block-poly (tetramethylene glycol) enhance the mechanical performance of polyamide-6. Eur. Polym. J. 2019, 110, 97-106. [CrossRef]

74. Rashmi, B.J.; Prashantha, K.; Lacrampe, M.F.; Krawczak, P. Scalable Production of Multifunctional Bio-Based Polyamide 11/Graphene Nanocomposites by Melt Extrusion Processes Via Masterbatch Approach. Adv. Polym. Technol. 2018, 37, 1067-1075. [CrossRef] 
75. Canales, J.; Fernández, M.; Peña, J.J.; Muñoz, M.E.; Santamaría, A. Rheological Methods to Investigate Graphene/Amorphous Polyamide Nanocomposites: Aspect Ratio, Processing, and Crystallization. Polym. Eng. Sci. 2015, 55, 1142-1151. [CrossRef]

76. Zhang, X.X.; He, J.X.; Wei, P.; Huang, X.; Tian, H.M.; Chen, M. Preparation and Properties of Nylon 6,6 Grafted Graphene Composites. J. Nanosci. Nanotechnol. 2020, 20, 1977-1982.

77. De Melo, C.C.N.; Beatrice, C.A.G.; Pessan, L.A.; de Oliveira, A.D.; Machado, F.M. Analysis of nonisothermal crystallization kinetics of graphene oxide-reinforced polyamide 6 nanocomposites. Thermochim. Acta 2018, 667,111-121. [CrossRef]

78. Aranburu, N.; Otaegi, I.; Guerrica-Echevarria, G. Using an Ionic Liquid to Reduce the Electrical Percolation Threshold in Biobased Thermoplastic Polyurethane/Graphene Nanocomposites. Polymers 2019, 11, 435. [CrossRef]

79. Alamgir, M.; Nayak, G.C.; Mallick, A.; Tiwari, S.K.; Mondal, S.; Gupta, M. Processing of PMMA nanocomposites containing biocompatible GO and TiO2 nanoparticles. Mater. Manuf. Process. 2018, 33, 1291-1298. [CrossRef]

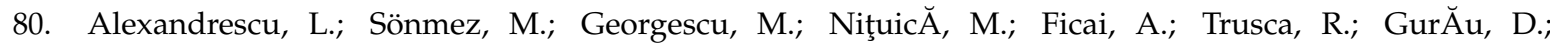
Tudoroiu, L. Polyamide/Polypropylene/graphene oxide nanocomposites with functional compatibilizers: Morpho-structural and physico-mechanical characterization. Procedia Struct. Integr. 2017, 5, 675-682. [CrossRef]

81. Muñoz, P.A.R.; de Oliveira, C.F.P.; Amurin, L.G.; Rodriguez, C.L.C.; Nagaoka, D.A.; Tavares, M.I.B.; Domingues, S.H.; Andrade, R.J.E.; Fechine, G.J.M. Novel improvement in processing of polymer nanocomposite based on 2D materials as fillers. Express Polym. Lett. 2018, 12, 930-945. [CrossRef]

82. Fajstavr, D.; Neznalová, K.; Švorčík, V.; Slepička, P. LIPSS Structures Induced on Graphene-Polystyrene Composite. Materials 2019, 12, 3460. [CrossRef] [PubMed]

83. Jyoti, J.; Dhakate, S.R.; Singh, B.P. Phase transition and anomalous rheological properties of graphene oxide carbon nanotube acrylonitrile butadiene styrene hybrid composites. Compos. Part B Eng. 2018, 154, 337-350. [CrossRef]

84. Jyoti, J.; Singh, B.P.; Chockalingam, S.; Joshi, A.G.; Gupta, T.K.; Dhakate, S.R. Synergetic effect of graphene oxide-carbon nanotube on nanomechanical properties of acrylonitrile butadiene styrene nanocomposites. Mater. Res. Express. 2018, 5, 045608. [CrossRef]

85. Tambrallimath, V.; Keshavamurthy, R.; Saravanabavan, D.; Koppad, P.G.; Kumar, G.S.P. Thermal behavior of PC-ABS based graphene filled polymer nanocomposite synthesized by FDM process. Compos. Commun. 2019, 15, 129-134. [CrossRef]

86. Oyarzabal, A.; Cristiano-Tassi, A.; Laredo, E.; Newman, D.; Bello, A.; Etxeberría, A.; Eguiazabal, J.I.; Zubitur, M.; Múgica, A.; Muller, A.J. Dielectric, mechanical and transport properties of bisphenol A polycarbonate/graphene nanocomposites prepared by melt blending. J. Appl. Polym. Sci. 2017, 134, 44654. [CrossRef]

87. Colonna, S.; Monticelli, O.; Gómez, J.; Saracco, G.; Fina, A. Morphology and properties evolution upon ring-opening polymerization during extrusion of cyclic butylene terephthalate and graphene-relatedmaterials into thermally conductive nanocomposites. Eur. Polym. J. 2017, 89, 57-66. [CrossRef]

88. Pena-Bahamonde, J.; San-Miguel, V.; Baselga, J.; Fernandez-Blazquez, J.P.; Gedler, G.; Ozisik, R.; Cabanelas, J.C. Effect of polysulfone brush functionalization on thermo-mechanical properties of melt extruded graphene/polysulfone nanocomposites. Carbon 2019, 151, 84-93. [CrossRef]

89. Xing, J.; Xu, Z.Z.; Ni, Q.Q.; Ke, H.Z. Preparation and characterization of polyphenylene sulfide/graphene nanoplatelets composite fibers with enhanced oxidation resistance. High Perform. Polym. 2019, 0954008319867748. [CrossRef]

90. Wu, Y.; Liu, Q.; Heng, Z.G.; Zou, H.W.; Chen, Y.; Liang, M. Improved mechanical properties of graphene oxide/short carbon fiber-polyphenylene sulfide composites. Polym. Compos. 2019, 40, 3866-3876. [CrossRef]

91. Tong, J.; Huang, H.X.; Wu, M. Promoting compatibilization effect of graphene oxide on immiscible PS/PVDF blend via water-assisted mixing extrusion. Compos. Sci. Technol. 2017, 149, 286-293. [CrossRef]

92. Tong, J.; Huang, H.X.; Wu, M. Simultaneously facilitating dispersion and thermal reduction of graphene oxide to enhance thermal conductivity of poly(vinylidene fluoride)/graphene nanocomposites by water in continuous extrusion. Chem. Eng. J. 2018, 348, 693-703. [CrossRef] 
93. Hou, X.C.; Hu, Y.; Hu, X.Y.; Jiang, D. Poly (ether ether ketone) composites reinforced by graphene oxide and silicon dioxide nanoparticles: Mechanical properties and sliding wear behaviour. High Perform. Polym. 2018, 30, 406-417. [CrossRef]

94. King, J.A.; Tomasi, J.M.; Klimek-McDonald, D.R.; Miskioglu, I.; Odegard, G.M.; King, T.R.; Sutherland, J.W. Effects of carbon fillers on the conductivity and tensile properties of polyetheretherketone composites. Polym. Compos. 2018, 39, E807-E816. [CrossRef]

95. The New Plastics Economy: Rethinking the Future of Plastics. Available online: www. ellenmacarthurfoundation.org/publications/the-new-plastics-economy-rethinking-the-future-of-plastics (accessed on 30 December 2019).

96. Geyer, R.; Jambeck, J.R.; Lavender Law, K. Production, use, and fate of all plastics ever made. Sci. Adv. 2017, 3, e1700782. [CrossRef]

97. Porta, R. The Plastics Sunset and the Bio-Plastics Sunrise. Coatings 2019, 9, 526. [CrossRef]

98. Singh, D.; Singh, R.; Boparai, K.S. Development and surface improvement of FDM pattern based investment casting of biomedical implants: A state of art review. J. Manuf. Process. 2018, 31, 80-95. [CrossRef]

99. Masood, S.H. Advances in Fused Deposition Modeling. Compr. Mater. Process. 2014, 69-91. [CrossRef]

100. Caminero, M.A.; Chacón, J.M.; García-Moreno, I.; Reverte, J.M. Interlaminar bonding performance of 3D printed continuous fiber reinforced thermoplastic composites using fused deposition modelling. Polym. Test. 2018, 68, 415-423. [CrossRef]

101. Kim, I.H.; Jeong, Y.G. Polylactide/exfoliated graphite nanocomposites with enhanced thermal stability, mechanical modulus, and electrical conductivity. J. Polym. Sci. Part B Polym. Phys. 2010, 48, 850-858. [CrossRef]

102. Gao, Y.Q.; Picot, O.T.; Tu, W.; Bilotti, E.; Peijs, T. Multilayer coextrusion of graphene polymer nanocomposites with enhanced structural organization and properties. J. Appl. Polym. Sci. 2018, 135, 46041. [CrossRef]

103. Chakraborty, G.; Gupta, A.; Pugazhenthi, G.; Katiyar, V. Facile dispersion of exfoliated graphene/PLA nanocomposites via in situ polycondensation with a melt extrusion process and its rheological studies. J. Appl. Polym. Sci. 2018, 135, 46476. [CrossRef]

104. Botta, L.; Scaffaro, R.; Sutera, F.; Mistretta, M.C. Reprocessing of PLA/Graphene Nanoplatelets Nanocomposites. Polymers 2018, 10, 18. [CrossRef]

105. Li, M.X.; Kim, S.H.; Choi, S.W.; Goda, K.; Lee, W.I. Effect of reinforcing particles on hydrolytic degradation behavior of poly (lactic acid) composites. Compos. Part B Eng. 2016, 96, 248-254. [CrossRef]

106. Chakraborty, G.; Valapa, R.B.; Pugazhenthi, G.; Katiyar, V. Investigating the properties of poly (lactic acid)/exfoliated graphene based nanocomposites fabricated by versatile coating approach. Int. J. Biol. Macromol. 2018, 113, 1080-1091. [CrossRef] [PubMed]

107. Batakliev, T.; Petrova-Doycheva, I.; Angelov, V.; Georgiev, V.; Ivanov, E.; Kotsilkova, R.; Casa, M.; Cirillo, C.; Adami, R.; Sarno, M.; et al. Effects of Graphene Nanoplatelets and Multiwall Carbon Nanotubes on the Structure and Mechanical Properties of Poly(lactic acid) Composites: A Comparative Study. Appl. Sci. 2019, 9, 469. [CrossRef]

108. Kotsilkova, R.; Angelova, P.; Batakliev, T.; Angelov, V.; Di Maio, R.; Silvestre, C. Study on Aging and Recover of Poly (Lactic) Acid Composite Films with Graphene and Carbon Nanotubes Produced by Solution Blending and Extrusion. Coatings 2019, 9, 359. [CrossRef]

109. Angelova, P. Mechanical and thermal properties of pla based nanocomposites with graphene and carbon nanotubes. J. Theor. Appl. Mech. 2019, 49, 241-256.

110. Zheng, L.; Geng, Z.X.; Zhen, W.J. Preparation, characterization, and reaction kinetics of poly (lactic acid)/amidated graphene oxide nanocomposites based on reactive extrusion process. J. Polym. Res. 2019, 26, 78. [CrossRef]

111. Wang, D.Z.; Lu, X.; Qu, J.P. Role of In situ thermal-reduced graphene oxide on the morphology and properties of biodegradable poly(Lactic acid)/poly(butylene succinate) blends. Polym. Compos. 2018, 39, 3057-3065. [CrossRef]

112. Ferreira, W.H.; Dahmouche, K.; Andrade, C.T. Tuning the Mechanical and Electrical Conductivity Properties of Graphene-Based Thermoplastic Starch/Poly(Lactic Acid) Hybrids. Polym. Compos. 2019, 40, E1131-E1142. [CrossRef]

113. Bher, A.; Unalan, I.U.; Auras, R.; Rubino, M.; Schvezov, C.E. Toughening of Poly(lactic acid) and Thermoplastic Cassava Starch Reactive Blends Using Graphene Nanoplatelets. Polymers 2018, 10, 95. [CrossRef] [PubMed] 
114. Barletta, M.; Trovalusci, F.; Puopolo, M.; Tagliaferri, V.; Vesco, S. Engineering and Processing of Poly(HydroxyButyrate) (PHB) Modified by Nano-sized Graphene Nanoplatelets (GNP) and AminoFunctionalized Silica (A-fnSiO(2)). J. Polym. Environ. 2016, 1, 1-11. [CrossRef]

115. Larsson, M.; Hetherington, C.J.D.; Wallenberg, R.; Jannasch, P. Effect of hydrophobically modified graphene oxide on the properties of poly(3-hydroxybutyrate-co-4-hydroxybutyrate). Polymer 2017, 108, 66-77. [CrossRef]

116. Cooper, C.J.; Abdelwahab, M.A.; Mohanty, A.K.; Misra, M. Hybrid Green Bionanocomposites of Bio-based Poly(butylene succinate) Reinforced with Pyrolyzed Perennial Grass Microparticles and Graphene Nanoplatelets. ACS Omega 2019, 4, 20476-20485. [CrossRef]

117. Gouvea, R.F.; Del Aguila, E.M.; Paschoalin, V.M.F.; Andrade, C.T. Extruded hybrids based on poly(3hydroxybutyrate-co-3-hydroxyvalerate) and reduced graphene oxide composite for active food packaging. Food Packag. Shelf. Life 2018, 16, 77-85. [CrossRef]

C 2020 by the authors. Licensee MDPI, Basel, Switzerland. This article is an open access article distributed under the terms and conditions of the Creative Commons Attribution (CC BY) license (http://creativecommons.org/licenses/by/4.0/). 